\title{
PD-L1/PD-L2/VISTA Antagonist CA-170
}

National Cancer Institute

\section{Source}

National Cancer Institute. PD-L1/PD-L2/VISTA Antagonist CA-170. NCI Thesaurus. Code C129594.

An orally bioavailable small molecule inhibitor of the immune checkpoint regulatory proteins programmed cell death ligand-1 (PD-L1; B7-H1; CD274), PD-L2, and V-domain immunog lobulin (Ig) suppressor of T-cell activation (VISTA; programmed death 1 homolog; PD1H; PD-1H), with potential negative immune checkpoint regulatory and antineoplastic activities. Upon oral administration, PD-L1/PD-L2/VISTA antagonist CA170 targ ets and binds to PD-L1, PD-L2 and VISTA. This inhibits PD-L1/PD-L2/VISTAmediated signaling, abrogates the PD-L1-, PD-L2- and VISTA-induced suppression of Tlymphocyte immune responses, enhances cytotoxic $\mathrm{T}$-cell proliferation and activation against tumor cells, increases cytokine production by T-cells, and inhibits tumor cell growth. PD-L1, PD-L2 and VISTA, negative checkpoint molecules of immune activation, play key roles in the suppression of T-cell functions. 